\title{
Eficiência de uso dos fatores de produção água e potássio na cultura da melancia irrigada com água de reúso ${ }^{1}$
}

\author{
Paulo G. F. de O liveira ${ }^{2}$, O lavo da C. Moreira2, Lourenço M. C. Branco ${ }^{2}$, \\ Raimundo N. T. Costa ${ }^{3} \&$ Chrislene N. Dias ${ }^{2}$
}

\begin{abstract}
RESU M O
A pesquisa foi desenvolvida no Núcleo $C$ do Perímetro Irrigado Curu Pentecoste, Ceará, em área de produção familiar e teve como objetivo a obtenção da eficiência de uso dos fatores de produção água e potássio para o cultivo da melancia com reúso de água da irrigação por sulcos em sistema localizado. 0 delineamento foi em blocos completos casualizados com parcelas subdivididas e quatro repetições. Os tratamentos de irrigação aplicados nas parcelas se constituíram de cinco níveis: 25, 75, 100, 150 e $200 \%$ da lâmina máxima evapotranspirada pela cultura e os níveis de potássio, dispostos nas subparcelas, aplicando-se as seguintes dosagens: sem a aplicação de $\mathrm{K}_{2} \mathrm{O}$ (testemunha), 30, 60 e $120 \mathrm{~kg} \mathrm{ha}^{-1}$ de $\mathrm{K}_{2} \mathrm{O}$. 0 nível de potássio associado à recomendação da análise de solo $\left(60 \mathrm{~kg} \mathrm{ha}^{-1}\right)$ proporcionou a máxima eficiência média de uso da água além de um incremento de 180,6 $\mathrm{kg} \mathrm{ha}^{-1}$ de melancia para cada kg ha-1 aplicado a mais de $\mathrm{K}_{2} \mathrm{O}$.
\end{abstract}

Palavras-chaves: Citrullus lanatus, produtividade, adubação potássica

\section{Efficiency of use of production factors water and potassium in the watermelon crop irrigated with water of reuse}

\begin{abstract}
A B STRACT
The research was conducted at Irrigated Perimeter of Curu Pentecoste, in an area of family cultivation and aimed to obtain the efficiency of use of water and potassium in the watermelon crop with reuse of irrigation water in furrow irrigation system. A completely randomized block design with split plots and four replications was used. Five irrigation levels were applied to the plots: $25,75,100,150$ and $200 \%$ of maximum crop evapotranspiration. The following levels of potassium fertilization were applied in the subplots: $0,30,60$ and $120 \mathrm{~kg} \mathrm{ha}^{-1}$ of $\mathrm{K}_{2} \mathrm{O}$. The potassium level associated with the recommendation of soil analysis $\left(60 \mathrm{~kg} \mathrm{ha}^{-1}\right)$ provided the highest average efficiency of water use and resulted in an increase of $180.6 \mathrm{~kg} \mathrm{ha}^{-1}$ of watermelon for each $\mathrm{kg} \mathrm{ha}^{-1}$ of $\mathrm{K}_{2} \mathrm{O}$ applied.
\end{abstract}

Key words: Citrullus lanatus, productivity, potassium compost

\footnotetext{
${ }_{1}^{1}$ Parte do relatório de pesquisa "Estratégias para reuso de água de drenagem em sistemas de irrigação localizada no Perímetro Irrigado Curu Pentecoste, Ceará. Edital: MCT/CN Pq/CT-AGRONEG Ó CIO/CT-HID RO - N 27/2008". Trabalho apresentado durante a II Reunião Sulamericana para Manejo e Sustentabilidade da Irrigação em Regiões Áridas e Semiáridas, Cruz das Almas, BA - 03 a 07 de abril de 2011

${ }^{2}$ Graduando, DEA/ UFC, Fortaleza, CE. E-mail: moreira_olavo@yahoo.com.br

${ }^{3}$ Depto. de Engenharia Agrícola, UFC, Fortaleza, CE. E-mail: rntcosta@secrel.com.br
} 


\section{INTRODUÇÃO}

A melancia (Citrullus lanatus) pertence à família das cucurbitáceas, tem grande expressão econômica e social, possuindo propriedades nutricionais e terapêuticas que aumentam o interesse do consumidor pelo seu fruto (Dias et al., 2006). Devido ao fácil manuseio e menor custo de produção, tem grande importância socioeconômica para os pequenos agricultores da região Nordeste do País, quando comparada a outras culturas sob condição de chuva ou irrigação. Entretanto, eventos de seca têm inibido a expressão desse potencial, o que faz da irrigação atividade importante em empreendimentos agrícolas.

A irrigação das áreas produtivas constitui alternativa para a melhoria do rendimento de grande maioria das culturas, proporcionando um incremento de produtividade da ordem de 200\% (Gonzaga Neto, 2000) e, com isto, redução dos custos por unidade de produto. Entretanto, somente com projetos corretamente dimensionados seguindo um manejo racional da água de irrigação que não degrade o ambiente, é que os irrigantes poderão usufruir da plenitude dos benefícios oriundos da irrigação (Castro et al., 2002).

Por outro lado, a crescente demanda por alimentos em virtude do aumento da população mundial, e a melhoria da qualidade de vida nas próximas décadas, deverão ser supridas pela agricultura irrigada; no entanto, a entrada de água por unidade de área irrigada terá de ser reduzida em resposta às preocupações à eminente crise da oferta de água no mundo (Playán \& Mateos, 2006).

Neste contexto, o reúso de água da atividade doméstica ou da água de drenagem para irrigação, surge como alternativa para aumentar a oferta de água, garantindo economia do recurso e racionalização do uso desse bem com a utilização de água não potável, em detrimento da água tratada e potável. A reutilização pode propiciar flexibilidade suficiente para o atendimento das demandas de curto prazo, assim como assegurar o aumento da garantia no suprimento em longo prazo.

O potássio desempenha muitas funções na bioquímica e fisiologia da planta, destacando sua participação nos processos de fotossíntese, transporte e armazenamento de assimilados. É requerido em grande quantidade pelas culturas, sendo o cátion mais abundante nos vegetais (Malavolta \& Crocomo, 1982; Mengel \& Kirkby, 1987; Marschner, 1995).

Kano et al. (2010) concluíram, avaliando a influência de doses de potássio nos teores de macronutrientes em plantas e sementes de alface que, em conjunto com o nitrogênio, o potássio é um dos elementos mais extraídos pelas plantas e sua deficiência ocasiona reduções no crescimento e na formação da "cabeça" de alface. Já Grangeiro \& Cecílio Filho (2002), afirmam que a exigência de potássio pela cultura da melancia (Citrullus lanatus) é superior à de nitrogênio, sendo exigido em maior proporção após a frutificação. Na cultura da melancia o cloreto de potássio é a fonte mais utilizada em virtude o menor preço; entretanto, não existem pesquisas que comprovem a maior eficiência dessa fonte para a cultura (Grangeiro \& Cecílio Filho, 2004).

O objetivo do trabalho foi analisar o efeito das lâminas totais da água, da adubação potássica e da interação desses dois fatores sobre a produtividade da cultura da melancia (Citrullus lanatus), variedade "Crimson Sweet", utilizando-se sistema de irrigação localizada com reúso de água proveniente do excedente da irrigação por sulcos.

\section{Material E MÉTODOS}

A pesquisa foi desenvolvida no Núcleo $\mathrm{C}$ do Perímetro Irrigado Curu - Pentecoste, e teve como objetivo analisar o efeito das lâminas totais de água, da adubação potássica e da interação desses fatores sobre a produtividade da cultura da melancia (Citrullus lanatus), variedade "Crimson Sweet", utilizando-se sistema de irrigação localizada com reúso de água proveniente do excedente da irrigação por sulcos.

A semeadura foi feita em bandejas de isopor de 128 células no dia 23 de setembro de 2010 com sementes certificadas. $\mathrm{Na}$ adubação de fundação utilizaram-se $3 \mathrm{~L}$ de esterco curtido e $270 \mathrm{~kg} \mathrm{ha}^{-1}$ de superfosfato simples e $60 \mathrm{~kg} \mathrm{ha}^{-1}$ de uréia.

A adubação nitrogenada de cobertura foi realizada através de fertirrigação em intervalos semanais; sete dias após o transplantio utilizaram-se $150 \mathrm{~kg} \mathrm{ha}^{-1}$ de uréia durante todo o ciclo. Quanto à adubação potássica foi realizada manualmente, em cobertura, de acordo com os tratamentos predefinidos.

O delineamento experimental foi de blocos completos casualizados com quatro parcelas subdivididas e quatro repetições, considerando-se dezesseis plantas por parcela e quatro plantas úteis por subparcela.

Os tratamentos de irrigação aplicados nas parcelas se compuseram de cinco níveis da lâmina máxima evapotranspirada da cultura $(25,75,100,150$ e 200\%) e, nas subparcelas, dosagens de adubação potássica (sem a aplicação de $\mathrm{K}_{2} \mathrm{O} 0$ (testemunha), 30, 60 e $120 \mathrm{~kg} \mathrm{ha}^{-1}$ de $\mathrm{K}_{2} \mathrm{O}$ ). Os tratamentos foram realizados através da aplicação convencional e fracionados em três épocas: 15,25 e 50 dias após a germinação.

Utilizou-se um sistema de irrigação localizado constituído de uma tubulação secundária (PVC) de $50 \mathrm{~mm}$ de diâmetro, com linhas laterais de tubo de polietileno de $16 \mathrm{~mm}$, gotejadores do tipo Microjet, espaçados $0,3 \mathrm{~m}$, apresentando vazão de $11 \mathrm{~L} \mathrm{~h}^{-1}$, conforme teste realizado no sistema, no total de dois por planta, além de um sistema de bombeamento constituído por uma motobomba com vazão total de $10,0 \mathrm{~m}^{3} \mathrm{~h}^{-1}$ e potência de $1,5 \mathrm{CV}$. A água foi bombeada de um dreno que coleta água excedente da irrigação por sulcos localizados ao lado do experimento.

O tempo de irrigação foi calculado de acordo com a Eq. 1.

$$
\mathrm{Ti}=\frac{\text { ECA.Kt.Kc.Kr.Ap }}{\mathrm{N} \cdot \mathrm{Qe}}
$$

em que:
Ti - tempo de irrigação, $h$
ECA - evaporação do tanque "classe A", mm
$\mathrm{Kt}$ - coeficiente do tanque
Kc - coeficiente de cultivo da cultura
$\mathrm{Kr}$ - coeficiente de redução
Ap - área útil por planta, $\mathrm{m}^{2}$ 
$\mathrm{N}$ - número de emissores

Qe - vazão do emissor, $\mathrm{L} \mathrm{h}^{-1}$

A eficiência de uso da água (EUA) foi obtida pelo quociente entre a produtividade da cultura e o volume total de água aplicado durante o ciclo:

$$
\mathrm{EUA}=\frac{\mathrm{Y}}{\mathrm{I}}
$$

em que:

$\mathrm{Y}$ - produtividade, $\mathrm{kg} \mathrm{ha}^{-1}$

I - volume de água aplicado por unidade de área, $\mathrm{m}^{3} \mathrm{ha}^{-1}$

A eficiência do uso do potássio (EUK) foi calculada utilizando-se a equação seguinte:

$$
\mathrm{EUK}=\frac{\mathrm{Yt}-\mathrm{Yo}}{\mathrm{Kt}}
$$

em que:

$\mathrm{Y}_{\mathrm{t}}$ - produtividade, $\mathrm{kg} \mathrm{ha}^{-1}$, da melancia no tratamento ' $\mathrm{t}$ '

$\mathrm{Y}_{0}$ - produtividade, $\mathrm{kg} \mathrm{ha}^{-1}$, da melancia no tratamento testemunha

$\mathrm{P}_{\mathrm{t}}$ - quantidade de $\mathrm{P}, \mathrm{kg} \mathrm{ha}^{-1}$, no tratamento ' $\mathrm{t}$ '.

\section{RESULTADOS E DISCUSSÃO}

A máxima produtividade média obtida foi de 38,63 ton ha-1 referente ao tratamento $\mathrm{W}_{4} \mathrm{~K}_{2}$ que corresponde a um volume de água aplicado de $2.510 \mathrm{~m}^{3} \mathrm{ha}^{-1}$ (150\% da lâmina evapotranspirada) e a uma dose de potássio de $60 \mathrm{~kg} \mathrm{ha}^{-1}$, essa máxima produtividade foi conseguida devido, provavelmente, à manutenção dos teores de água no solo adequados para a cultura possibilitando uma absorção maior de água e nutrientes, promovendo também uma proporção maior de fotoassimilados translocados das folhas para outros órgãos, principalmente em plantas bem nutridas de potássio; já a menor produtividade, $11,87 \mathrm{t} \mathrm{ha}^{-1}$, foi observada no tratamento $\mathrm{W}_{1} \mathrm{~K}_{0}$, equivalente a um volume de água aplicado de $619 \mathrm{~m}^{3} \mathrm{ha}^{-1} \mathrm{e}$ sem a aplicação de potássio aplicado (Tabela 1). Esses resultados demonstram que ambos os fatores são limitantes à produtividade da cultura.

Aumentos significativos na produção de melancia em função da adubação potássica também foram observados por Zeng \& Jiang (1988), Simone \& Smittle (1992) e Locascio \& Hochmuth (2002).

Batista et al. (2008) observaram, avaliando a produtividade da melancia Crimson Sweet irrigada por gotejamento submetida a diferentes espaçamentos e lâminas de irrigação, uma máxima produtividade de 44,46 t ha-1 ao aplicarem $120 \%$ da lâmina evapotranspirada pela cultura. Azevedo et al. (2005) observaram uma máxima produtividade média de $25,33 \mathrm{t} \mathrm{ha}^{-1}$ obtida no tratamento ao que aplicava uma lâmina referente a $100 \%$ da ECAe o menor valor da produtividade foi de $10,16 \mathrm{t} \mathrm{ha}^{-1}$ no tratamento de $25 \%$ da ECA. Teodoro et al. (2004) obtiveram a máxima produtividade $\left(44,96\right.$ t ha $\left.^{-1}\right)$ com o nível de irrigação $120 \%$ da ECA.

Andrade Júnior et al. (2005) observam, nas condições climáticas de Parnaíba, PI, o máximo rendimento comercial de 57,93 tha ${ }^{-1}$ para a dose de $80 \mathrm{~kg} \mathrm{ha}^{-1}$ de $\mathrm{K}_{2} \mathrm{O}$, valor este bastante superior ao encontrado no presente estudo, por Cecílio Filho \& Grangeiro (2004) que alcançaram produtividade comercial média de 34,40 $\mathrm{Mg} \mathrm{ha}^{-1}$, em Borborema, SP, utilizando o híbrido Tide como, também, aos encontrados por Garcia \& Souza (2002), que alcançaram produtividade comercial média de $46,6 \mathrm{Mg} \mathrm{ha}^{-1}$, utilizando cv. Crimson Sweet nas condições climáticas de Parnaíba.

$\mathrm{O}$ resumo da análise de variância da produtividade da melancia, de $\mathrm{kg} \mathrm{ha}^{-1}$ está apresentado na Tabela 2. A análise mostrou que ambos os fatores de produção, água e dosagens de potássio, foram significativos a nível de $1 \%$ de probabilidade ( $\mathrm{p}<0,01)$, as mesma forma que a interação entre ambos. Verificase, ainda, que o efeito do potássio sobre o rendimento da cultura foi muito mais pronunciado que o da água. Morais et al. (2008), Soares et al. (2002) observaram, estudando a cultura da melancia, resultados semelhantes ao estudarem o efeito de lâminas de água e níveis de nitrogênio, observando que a água

\begin{tabular}{|c|c|c|c|c|c|c|}
\hline \multirow{2}{*}{\multicolumn{2}{|c|}{$\begin{array}{l}\text { Lâmina de água } \\
\text { aplicada }\left(\mathrm{m}^{3} \mathrm{ha}^{-1}\right)\end{array}$}} & \multicolumn{4}{|c|}{ Níveis de $K_{2} \mathrm{O}\left(\mathrm{kg} \mathrm{ha}^{-1}\right)$} & \multirow[b]{2}{*}{ Médias } \\
\hline & & \multirow{2}{*}{$\begin{array}{c}\mathbf{K}_{\mathbf{0}} \\
\mathbf{0} \\
11.877,15\end{array}$} & \multirow{2}{*}{$\begin{array}{c}\mathbf{K}_{1} \\
30,0 \\
13.855,83\end{array}$} & \multirow{2}{*}{$\begin{array}{c}\mathrm{K}_{2} \\
60,0 \\
20.641,04\end{array}$} & \multirow{2}{*}{$\begin{array}{c}\mathrm{K}_{3} \\
120,0 \\
17.121,18\end{array}$} & \\
\hline $\mathrm{W}_{1}$ & 619 & & & & & $15.873,80$ \\
\hline$W_{2}$ & 1335 & $15.160,03$ & $26.117,88$ & $26.211,57$ & $20.766,73$ & $22.064,05$ \\
\hline$W_{3}$ & 1712 & $18.317,03$ & $25.528,29$ & $27.661,39$ & $25.737,32$ & $24.311,01$ \\
\hline $\mathrm{W}_{4}$ & 2510 & $17.868,00$ & $35.699,19$ & $38.638,48$ & $20.698,33$ & $28.226,00$ \\
\hline$W_{5}$ & 3292 & $18.446,55$ & $21.046,25$ & $22.697,68$ & $21.323,34$ & $20.878,46$ \\
\hline \multicolumn{2}{|c|}{ Médias } & $16.333,75$ & $24.449,49$ & $27.170,03$ & $21.129,38$ & \\
\hline
\end{tabular}

Tabela 1. Produtividade média de melancia sob diferentes lâminas de água de reúso e doses de potássio

Tabela 2. Resumo da análise de variância da produtividade de melancia sob diferentes lâminas (volume) de água de

\begin{tabular}{|c|c|c|c|c|c|c|c|}
\hline \multirow[b]{2}{*}{ Variável analisada } & \multicolumn{7}{|c|}{$\mathbf{F}$} \\
\hline & $\begin{array}{l}\text { Volume } \\
\text { de água }\end{array}$ & $\begin{array}{l}\text { Regressão } \\
\text { linear }\end{array}$ & $\begin{array}{l}\text { Regressão } \\
\text { quadrática }\end{array}$ & K & $\begin{array}{l}\text { Regressão } \\
\text { linear }\end{array}$ & $\begin{array}{l}\text { Regressão } \\
\text { quadrática }\end{array}$ & Água $\times \mathrm{K}_{2} \mathrm{O}$ \\
\hline Produtividade & $11,29 * *$ & $14,32 * *$ & $25,25 * *$ & $25,46 * *$ & $17,11^{* *}$ & $58,60 * *$ & $3,68 * *$ \\
\hline
\end{tabular}
reúso e doses de potássio 
e o nitrogênio influenciaram significativamente o rendimento das culturas.

Observando a análise de regressão, nota-se efeito significativo para ambos os fatores de produção, seja para regressão linear ou para regressão quadrática. Entretanto, a regressão quadrática apresentou maior nível de significância e maior coeficiente de determinação demonstrando que a mesma explica melhor a resposta da produtividade da cultura aos tratamentos. Embora Vaux et al. (1981) citem que a relação entre a aplicação de água e o rendimento das culturas possa ser representada por vários modelos estatísticos, o modelo quadrático, segundo esses autores, tem-se mostrado adequado para representar tal relação. Morais et al. (2008), Azevedo et al. (2005) e Andrade Júnior et al. (1997) verificaram que o rendimento da melancia variou de forma quadrática com a aplicação da água.

Ao analisar o efeito do volume aplicado de água sobre a produtividade da melancia por meios de regressão quadrática, observam-se efeito altamente significativo $(\mathrm{F}=25,253$ e $\mathrm{p}<$ 0,001 ) e coeficiente de determinação de 0,9131 . Ao se estimar o nível tecnicamente ótimo desse fator de produção, se encontra um valor de $2.248,25 \mathrm{~m}^{3} \mathrm{ha}^{-1}$ correspondendo a uma produtividade de $26.624,01 \mathrm{~kg} \mathrm{ha}^{-1}$ em que este valor é menor que a máxima produtividade média de $28.226 \mathrm{~kg} \mathrm{ha}^{-1}$ observada para este fator de produção. Esta diferença pode ser explicada ao se atentar para a Figura 1, em que o valor observado se encontra acima da linha de tendência não sendo explicado, portanto, pela regressão quadrática.

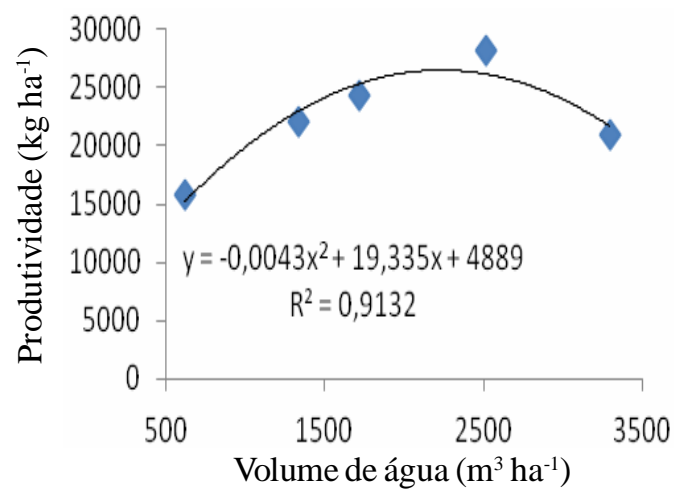

Figura 1. Produtividade da melancia (y) em função do volume de água (W)

O modelo quadrático em razão dos níveis de potássio, foi altamente significativo $(\mathrm{F}=58,601 \mathrm{p}<0,001)$, apresentando coeficiente de determinação de 0,9969 e explicando muito bem as relações de rendimento em função do insumo. Com isto, pode-se estimar por derivação o nível tecnicamente ótimo de produção da melancia, resultando em uma produtividade de $27.579,52 \mathrm{~kg} \mathrm{ha}^{-1}$, correspondendo a um nível de adubação potássica de $67,16 \mathrm{~kg} \mathrm{ha}^{-1}$ (Figura 2).

$\mathrm{Na}$ Tabela 3 se apresentam os valores médios de eficiência de uso da água $\left(\mathrm{kg} \mathrm{m}^{-3}\right)$ relacionada à cultura da melancia em função dos níveis de água aplicada e dos níveis de potássio. Observa-se um incremento nos valores médios de produtividade da água com o aumento das doses de potássio, até $60 \mathrm{~kg} \mathrm{ha}^{-1}$, ocorrendo decréscimo com valores acima deste,

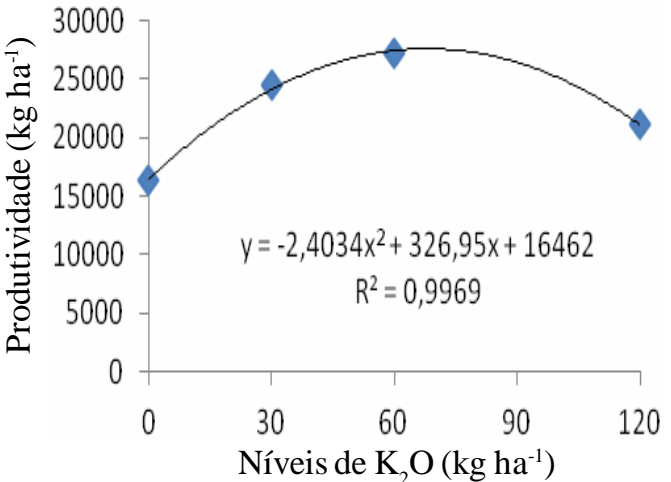

Figura 2. Produtividade da melancia (y) em função dos níveis de potássio $\left(\mathrm{K}_{2} \mathrm{O}\right)$

fato observado também por Moreira (2010), Monteiro et al. (2008) e Barros et al. (2002) avaliando o incremento da EUA sobre vários níveis de adubação. Lopes (1989) constatou que a eficiência do uso da água aumenta com a prática da adubação, desde que a produtividade também aumente.

Tabela 3. Eficiência de uso da água $\left(\mathrm{kg} \mathrm{m}^{-3}\right)$ de melancia sob diferentes lâminas de água e doses de potássio

\begin{tabular}{|c|c|c|c|c|c|c|}
\hline \multirow{2}{*}{\multicolumn{2}{|c|}{$\begin{array}{l}\text { Lâmina de água } \\
\text { aplicada }\left(\mathrm{m}^{3} \mathrm{ha}^{-1}\right)\end{array}$}} & \multicolumn{4}{|c|}{ Níveis de $\mathrm{K}_{2} \mathrm{O}\left(\mathrm{kg} \mathrm{ha}^{-1}\right)$} & \multirow[b]{2}{*}{ Médias } \\
\hline & & \multirow{2}{*}{$\begin{array}{c}\mathbf{K}_{0} \\
\mathbf{0 , 0} \\
19,19\end{array}$} & \multirow{2}{*}{$\begin{array}{c}K_{1} \\
30,0 \\
22,38\end{array}$} & \multirow{2}{*}{$\begin{array}{c}K_{2} \\
60,0 \\
33,34\end{array}$} & \multirow{2}{*}{$\begin{array}{c}K_{3} \\
120,0 \\
27,66\end{array}$} & \\
\hline$W_{1}$ & 619 & & & & & 25,64 \\
\hline $\mathrm{W}_{2}$ & 1335 & 11,36 & 19,57 & 19,64 & 15,56 & 16,53 \\
\hline$W_{3}$ & 1712 & 10,70 & 14,91 & 16,15 & 15,03 & 14,20 \\
\hline $\mathrm{W}_{4}$ & 2510 & 7,12 & 14,22 & 15,39 & 8,24 & 11,24 \\
\hline$W_{5}$ & 3292 & 5,60 & 6,39 & 6,89 & 6,48 & 6,34 \\
\hline \multicolumn{2}{|c|}{ Médias } & 10,79 & 15,49 & 18,28 & 14,59 & \\
\hline
\end{tabular}

A máxima produtividade da água observada $\left(33,34 \mathrm{~kg} \mathrm{~m}^{-3}\right)$ compreendeu o menor volume de água $\left(\mathrm{W}_{1}\right)$ aplicado e o nível de adubação potássica recomendado conforme análise de solo, indicando que plantas bem supridas nutricionalmente apresentam menores necessidades hídricas. Apesar desse nível de irrigação propiciar os maiores valores de eficiência de uso da água, observa-se uma redução de $77,8 \%$ na produtividade média da cultura, quando comparada com a do tratamento $\mathrm{W}_{4}$ $\left(2510 \mathrm{~m}^{3} \mathrm{ha}^{-1}\right)$ que propiciou a maior produtividade da cultura.

Culturas que apresentam maior eficiência do uso da água são de suma importância quando se fala em economia dos recursos hídricos, pois as mesmas possibilitam um rendimento maior por $\mathrm{m}^{3}$ de água. Verifica-se que as correlações entre eficiência de uso da água e os níveis dos insumos água e potássio são. respectivamente, positiva e negativa, conforme ilustram as Figuras 3 e 4.

Moreira (2010) observou, avaliando a eficiência de uso da água na cultura da abóbora, uma máxima eficiência de 18,7 $\mathrm{kg} \mathrm{m}^{-3}$, correspondendo a um volume de água aplicado de 938,2 $\mathrm{m}^{3} \mathrm{ha}^{-1}$, utilizando sistema de irrigação localizada, valor parecido ao observado por Melo et al. (2010) que, avaliando o rendimento da melancia sob diferentes níveis de água, observaram uma máxima eficiência de 19,6 $\mathrm{kg} \mathrm{m}^{-3}$ aoaplicar uma lâmina de 266 $\mathrm{mm}$, durante todo o ciclo.

Os valores de eficiência de uso de potássio, EUK, para os tratamentos $\mathrm{K}_{0} \mathrm{~K}_{1}, \mathrm{~K}_{2} \mathrm{~K}_{3}$ foram: 0; 270,5; 180,6 e 39,9 $\mathrm{kg} \mathrm{ha}^{-1} / \mathrm{kg}$ $\mathrm{ha}^{-1}$, respectivamente. Esses dados se ajustam a uma função 


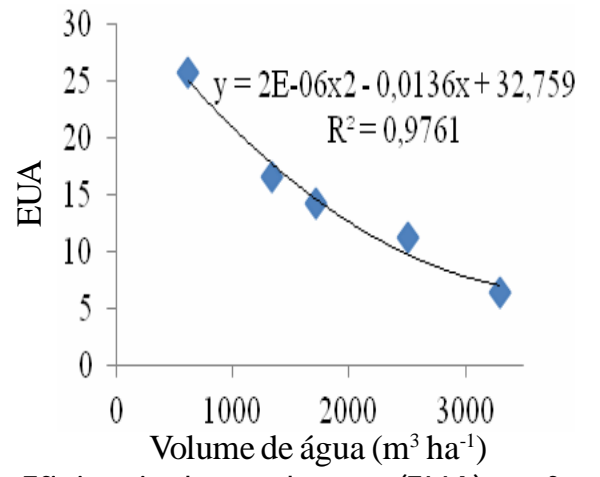

Figura 3. Eficiência de uso de água (EU A) em função do volume de água

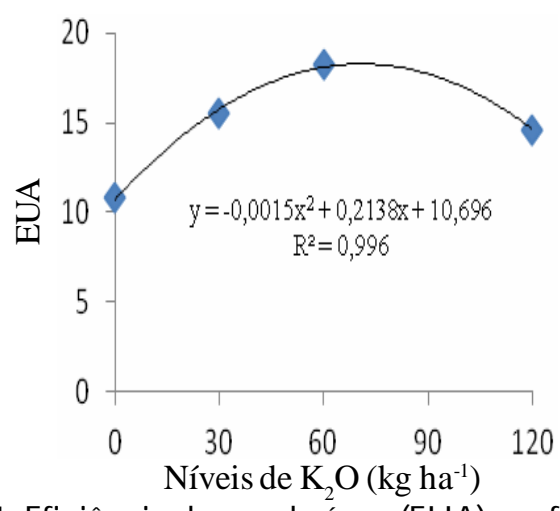

Figura 4. Eficiência de uso de água (EU A) em função do nível do potássio

quadrática, denotando uma região não racional de aplicação deste insumo a partir do nível equivalente a $60,0 \mathrm{~kg} \mathrm{ha}^{-1} \mathrm{de}$ $\mathrm{K}_{2} \mathrm{O}$, conforme se visualiza na Figura 5 .

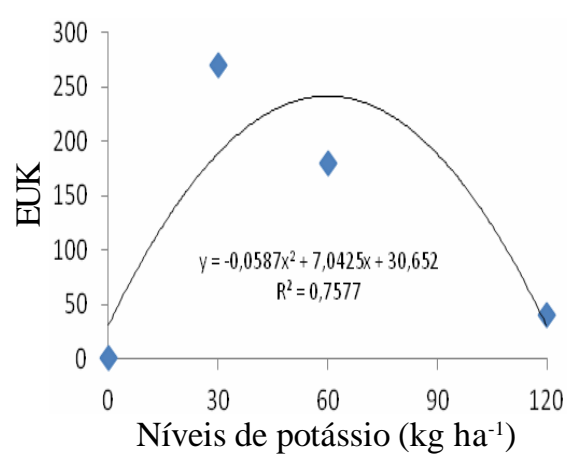

Figura 5. Eficiência de uso do potássio em função de níveis de potássio

Cecílio Filho \& Grangeiro (2004) observaram, avaliando a produtividade da melancia sob diferentes níveis e fontes de

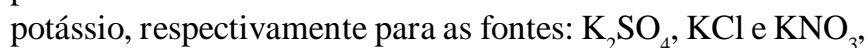
uma máxima eficiência de uso de $\mathrm{K}_{2} \mathrm{O}$ de 245,158 e $178 \mathrm{~kg} \mathrm{ha}^{-1}$.

Oliveira et al. (2008) e Amaro Filho et al. (2001) constataram, analisando eficiência nutricional do potássio em meloeiro, a máxima eficiência de uso deste insumo com níveis de adubação de respectivamente, 106 e $100 \mathrm{~kg}$ de $\mathrm{K}_{2} \mathrm{O} \mathrm{ha}^{-1}$. Comparado à testemunha, promoveu um incremento de $34,5 \%$ na produtividade (Amaro Filho et al, 2001); já na cultura da melancia verificou-se um incremento de $66 \%$ na produtividade.

\section{CONCLUSÕES}

1. A produtividade da cultura foi incrementada em $66 \%$ com o fator de produção potássio, o qual se mostrou limitante ao rendimento da cultura.

2. A máxima produtividade média da cultura ocorreu em um nível de irrigação acima do nível estimado para a necessidade hídrica da cultura.

3. Os valores médios de produtividade da cultura em relação aos níveis de potássio para o tratamento de menor nível de irrigação indicam que plantas bem supridas de potássio permitem compensar déficit hídrico, tendo em vista a possibilidade de substituição dos insumos.

4. O modelo quadrático explicou melhor a resposta da cultura e o nível tecnicamente ótimo estimado por este modelo foi próximo à recomendação para cultura.

5. O nível de potássio associado à recomendação da análise de solo proporcionou a máxima eficiência média de uso da água e um incremento de $180,6 \mathrm{~kg} \mathrm{ha}^{-1}$ de melancia para cada $\mathrm{kg} \mathrm{ha}^{-1}$ aplicado a mais de $\mathrm{K}_{2} \mathrm{O}$.

\section{Agradecimentos}

Os autores agradecem ao $\mathrm{CNPq} / \mathrm{CT}$-Hidro pelo financiamento da pesquisa; ao Programa Institucional de Bolsas de Iniciação Científica - PIBIC, à Universidade Federal do Ceará e aos agricultores familiares que participaram deste processo.

\section{LITERATURA CITADA}

Amaro Filho, J; Mota, J. C. A.; Sales Júnior, R.; Silva, E. de C. Eficiência nutricional para potássio em meloeiro. Horticultura Brasileira, v.21, p.374-374, 2003.

Andrade Júnior, A. S. de; Dias, N. da S.; Figueiredo Júnior, L. G. M.; Daniel, R.; Ribeiro, V. Q. Doses de potássio via fertirrigação na produção e qualidade de frutos de melancia em parnaíba, PI. Irriga, v.10, p.205-214, 2005.

Andrade Júnior, A. S. de; Rodrigues, B. H. N.; Sobrinho, C. A; Melo, F. de B.; Bastos, E. A; Cardoso, M. J.; Ribeiro, V. Q. Produtividade e qualidade de frutos de melancia em função de diferentes níveis de irrigação. Horticultura Brasileira, v.15, p.43-46, 1997.

Azevedo, B. M. de; Bastos; F. G. C.; Viana, T. V. de A.; Rêgo, J. de L.; D'Ávila, J. H. T. Efeitos de níveis de irrigação na cultura da melancia. Revista Ciência Agronômica, v.36, p. 915, 2005.

Barros, V. da S.; Costa, R. N. T.; Aguiar, J. V. Função de produção de cultura do melão para níveis de água e adubação nitrogenada no vale do Curu-CE. Irriga, v.7, p.98105, 2002.

Batista, P. F.; Karasawa, M.; Silva, N. C. da; Pires, M. M. M. da Luz; Pimenta, R. M. B.; Aragão, C. A. Produtividade da melancia irrigada por gotejamento submetida a diferentes espaçamentos e lâminas de irrigação. Horticultura Brasileira, v.26, p.S5706-S5709, 2008. 
Castro, R. S. de; Silva, I. J. O. da. Utilização de efluente de viveiro de peixes para a irrigação do tomate cereja cultivado em diferentes substratos. Horticultura Brasileira, v.20, p.917, 2002.

Cecílio Filho, A. B.; Grangeiro, L. C. Produtividade da cultura da melancia em função de fontes e doses de potássio. Ciência e Agrotecnologia, v.28, p.561-569, 2004.

Dias, R. C. S.; Silva, C. M. J.; Queiroz, M. A.; Costa, N. D.; Souza, F. F.; Santos, M. H.; Paiva, L. B.; Barbosa, G. S.; Medeiros, K. N. Desempenho agronômico de linhas de melancia com resistência ao oídio, Horticultura Brasileira, v.24, p.1416-1418, 2006.

Garcia, L. F.; Souza, V. A. B. Influência do espaçamento e da adubação nitrogenada sobre a produção da melancia. Revista de la Facultad de Agronomia, v.28, p.59-70, 2002.

Gonzaga Neto, L. Produtividade e competitividade dependem do aumento de hectares irrigados. Revista dos Agrônomos, v.3, p.14-20, 2000.

Grangeiro, L. C.; Cecílio Filho, A. B. Marcha de absorção de nutrientes pela cultura da melancia. In: Reunião Brasileira de Fertilidade do Solo e Nutrição de Plantas, 25, Reunião Brasileira Sobre Micorrizas, 9. Simpósio Brasileiro de Microbiologia do Solo, 7. Reunião Brasileira de Biologia do Solo, 4, 2002, Rio de Janeiro. Anais... Rio de Janeiro: [s.n.], 2002. CD-Rom

Grangeiro, L. C.; Cecílio Filho, A. B. Exportação de nutrientes pelos frutos de melancia em função de épocas de cultivo, fontes e doses de potássio. Horticultura Brasileira, v.22, p.740-743, 2004.

Kano, C; Cardoso, A. I. I.; Villas Bôas, Roberto, L. Influência de doses de potássio nos teores de macronutrientes em plantas e sementes de alface. Horticultura Brasileira, v.28, p.287$291,2010$.

Locascio, S. J.; Hochmuth, G. J. Watermelon production as influenced by lime, gypsum, and potassium. Horticultural Science, v.2, p.322-324, 2002.

Lopes, A. S. Manual de fertilidade do solo. São Paulo: ANDA/ Potafos, 1989. 153p.

Malavolta, E.; Crocomo, O. J. Funções do potássio nas plantas. In: Yamada, T.; Igue, K.; Muzilli, O.; Usherwood, N. R. Potássio na agricultura brasileira. Piracicaba: Potafos, 1982. p. 95-162.

Marschner, H. Mineral nutrition of higher plants. San Diego: Academic, 1995. 889p.
Melo, A. S. de; Suassuna, J. F.; Fernandes, P. D.; Brito, M. E. B.; Suassuna, A. F.; Aguiar Netto, A. de O.; Crescimento vegetativo, resistência estomática, eficiência fotossintética e rendimento do fruto da melancieira em diferentes níveis de água. Acta Scientiarum. Agronomy, v.32, p.73-79, 2010.

Mengel, K.; Kirkby, E. A. Copper, further elements of importance. In: Mengel, K.; Kirkby, E. A. Principles of plant nutrition. 4.ed. Berne: International Potash Institute, 1987. p.537-588.

Monteiro, R. O. C.; Costa, R. N. T.; Leão, M. C. S.; Aguiar, J. V. de. Eficiência do uso da água e nitrogênio na produção de melão. Irriga, v.13, p.367-377, 2008.

Morais, N. B. de,; Bezerra, F. M. L.; Medeiros, J. F. de; Chaves, S. W. P. Resposta de plantas de melancia cultivadas sob diferentes níveis de água e de nitrogênio. Revista Ciência Agronômica, v.39, p.369-377, 2008.

Moreira, O. C. Resposta da cultura da abóbora aos fatores de produção água e adubo nitrogenado com reuso de água da irrigação por sulcos em sistema de irrigação localizada, CE. UFC. Monografia, Fortaleza, 2010.

Oliveira, F.A. ; Medeiros, J. F. de; Lima, C. J. G. de S.; Dutra, I.; Oliveira, M. K, T. de. Eficiência agronômica da fertirrigação nitrogenada e potássica na cultura do meloeiro nas condições do semi-árido nordestino. Caatinga, v.21, p.5-11, 2008.

Playán, E.; Mateos, L. Modernization and optimization of irrigation systems to increase water productivity. Agricultural Water Management, v.80, p.100-116, 2006.

Simonne, E. H.; Smittle, D. A. Ammonium reduces growth fruit yield and fruit quality of watermelon. Journal of Plant Nutrition, v.15, p.2727-2741, 1992.

Soares, J. I.; Costa, R. N. T.; Silva, L. A. C. da; Gondim, R. S. Função de resposta da melancia aos níveis de água e adubaçãonitrogenada, no Vale do Curu, CE. Revista Brasileira de Engenharia Agrícola e Ambiental, v.6, p.219-224, 2002

Teodoro, R. E. F.; Almeida, F. P.; Luz, J. M. Q.; Melo, B. Diferentes lâminas de irrigação por gotejamento na cultura de melancia (Citrullus lanatus). Bioscience Journal, v.20, p.29-32, 2004.

Vaux Jr., H. J.; Pruitt, W. O.; Hatchett, S. A.; Souza, F. de. Optimization of water use with respect to crop production. Resources and environmental economics and public policy group. Davis: Riverside/University of California, 1981. 174p. Working Paper Series

Zeng, Q. Y.; Jiang, X. L. Influence of potash fertilizers contaiming chlorine on the quality of watermelon. Soil, Baltimore, v.20, p.144-146, 1988. 